\title{
Continuities and Discontinuities in the Vernacular Architecture
}

\author{
By Maria Philokyprou*
}

Vernacular architecture has been growing over time with continuities, changes, transformations and adaptations to the different social and economic conditions of each period in response to actual needs with the available means of every place. Continuities in vernacular architecture are closely related to space, time and materiality and involve structural, typological, functional and social issues with multiple readings and interpretations. The recent abandonment of a large number of traditional dwellings mainly due to urbanization and the romantic nostalgia towards the past have led to the conservation and reuse of traditional buildings following a different approach compared to previous periods. The previous tactic of segmented partial and on-going maintenance without interrupting the continuity and use has been replaced today with an integrated comprehensive and thorough conservation and transformation of a building. Is conservation of vernacular architecture an act of continuity with the past or discontinuity within the context of the existing data and processes? When conserving traditional buildings is it possible to accomplish morphological, structural and social continuity? How is the potential integrity of traditional buildings achieved? These are some of the questions discussed in this paper with the focus of seeking a contemporary way of keeping alive and genuine the relationship with the cultural works of the past.

\section{Introduction}

Vernacular architecture is generally characterized by a continuous process over time, as it has been growing in response to actual needs with the available means of every place. At the same time some discontinuities can be observed in its path. What do these continuities and discontinuities imply? Is conservation of vernacular architecture an act of continuity or discontinuity?

Vernacular architecture, also referred to as traditional, anonymous, native or indigenous to a specific time and place, is the architecture of people (Paul Oliver 2005). It is related to the environmental context and available resources, it is customarily owner or community built, utilizing traditional technologies and local materials. All forms of vernacular architecture are built to meet

${ }^{*}$ Lecturer, University of Cyprus, Cyprus. 
specific needs, accommodating the values, economies and ways of life of the cultures that produce them.

Vernacular architecture as a continuous creation of life shows continuities and discontinuities through its routes and develops its own initiatives in the conditions of each period and area. The image of an existing building or historic center is not something static but is constantly subject to changes.

\section{Diachronical Development of Vernacular Architecture}

The continuity in vernacular architecture is related to space and time, involves structural, typological, functional and social issues and has multiple readings and interpretations. In the historic city centers continuities and discontinuities can be seen in the urban tissue. The traditional complexes follow the detached building system and therefore define clear borders and boundaries. In cohesive traditional complexes, an urban characteristic is the absence of gaps in the built space and the clearly formatted and immediately apparent limits to the surroundings. Nevertheless the recent evolution of the traditional urban and rural areas in some cases leads to the existence of vacant spaces which appear as voids in a continuous building system.

\section{Matters of Typology}

Vernacular architecture has always been timeless and continuous in architectural development according to space and function since traditional buildings acquired their final form as a result of extensions and additions to an initially smaller unit in order to satisfy the temporal requirements of the respective owner. Additions and extensions were usually designed on site and were implemented by the user himself or by some craftsmen. Diachronical development and various transformations of the more simple primitive forms have led to the creation of more complex forms and types.

In some villages of the island, such as Pano Pyrgos Tillyrias (Philokyprou 2009), very simple and primitive dwelling units - such as houses often consisting of one simple room (macrynari) - still exist, thus highlighting the simplicity of the original module from which more complex forms were later derived. It is evident that in urban centers the initial typology of the houses has its roots in rural traditional units that were diachronically transformed to more complex urban arrangements. The typical spaces of traditional housesmakrynari (long room), dichoro (double room), iliakos (semi-open space) and the inner courtyard- remained for a long period the main elements of composition in vernacular architecture that serve the needs of their respective occupants.

\section{Continuity in Materiality}

Recent studies have shown the existence of continuity in the manufacturing options of traditional materials and construction methods: selection of rocks, structural solutions and simple aesthetic inventions. A 
continuity in the materiality of buildings through time since the prehistoric period onwards to the traditional architecture of the last two centuries can easily be observed (same building materials - especially stone, mud bricks (Figure1) and mortars, same variety of stones - igneous, sedimentary rocks of different geological formations) (Figure 2).

Figure 1. Mud Brick Walls (a,b: Prehistoric Settlements, c,d: Traditional Buildings of the Last Centuries)
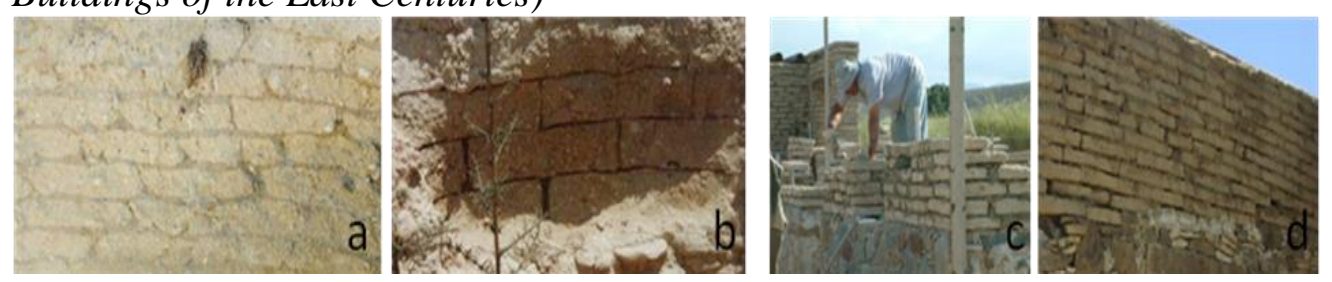

Similar methods of dressing and erection of stone walls have been used diachronically (Figure 2). Most of the walls followed the shell type building system with ashlars or large rubble stones used for the exterior faces of walls. A common characteristic of ashlar walls was the dressing and smoothing of only the faces that were meant to be visible and partly of the surfaces set against other stones leaving the back of the stone unworked (Philokyprou 2011).

Figure 2. Different Types of Stone Walls. Walls with Rubble Stones (a) Prehistoric Structure, (b) Traditional Dwelling and Walls with Ashlar Showing Drafted Margins (c) Prehistoric Structure, (d) Traditional Building
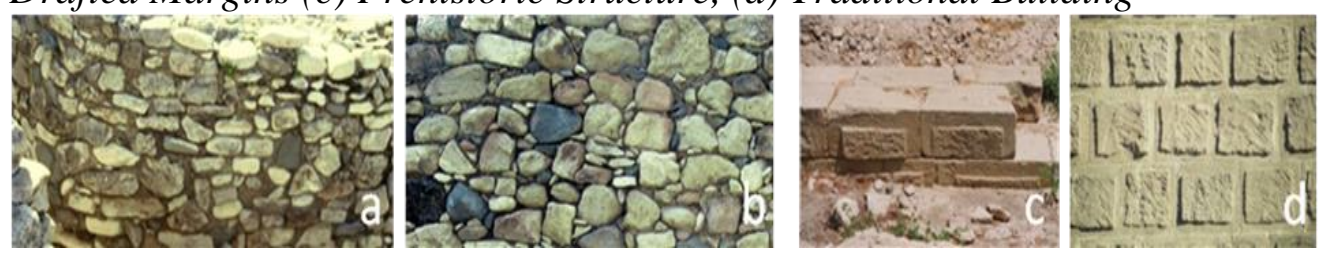

Structural reasons and especially the need for stability led the traditional builder to the erection of thick stone and mud brick walls of $50 \mathrm{~cm}$. At the same time the thickness of the wall has an interesting aesthetic result. The substitution of the original thick walls of the traditional way of building with thin walls in contemporary architecture leads to a substantial aesthetic construction change.

While the two main building materials, stone and mud brick, have lasted for centuries due to their resistance, mortars being the latest and most vulnerable layers are often being repeatedly replaced, and in many cases the final layers belong to the most recent past. However, the replacement of these plasters over time is part of the continuity of the life of buildings within the diachronical adjustments in order to continue to play an operational role. 


\section{Sustainable Design Elements used Diachronically in Vernacular Architecture}

The use of traditional local materials and available resources and also the incorporation of many bioclimatic features in the design of the traditional settlements give them a sustainable identity. Through their historic diversity, quality and continuity, the traditional settlements constitute non-renewable resources. The concept of sustainable development offers a new platform for the integration of the crucial aspects of cultural heritage into a larger social and economic strategy.

The sustainable design elements that characterize vernacular architecture using materials available in the area and environmentally friendly methods and simple forms constitute the source of inspiration of modern and contemporary architects in the design of buildings friendly to man and the environment (Aris Konstantinidis, Neoptolemos Michaelides). One such element is the central courtyard (Figure 3), the open space incorporated into the center of many houses in Cyprus, which has always constituted an important architectural feature throughout centuries (Michael and Philokyprou 2013). The erection of residences attached to each other, the need for a private outdoor space due to social factors and the warm Mediterranean climate led to a widespread use of the courtyard in nearly all the traditional residences of the island during the last two centuries. Beyond vernacular architecture, courtyards appeared in modernmovement architecture of Neoptolemos Michaelides, in Cyprus, even when the urban building system changed with the predominance of the detached-house system.

Figure 3. Houses with Central Courtyard - a,b: Vernacular Buildings, c,d: Modern Movement Houses of Neoptolemos Michaelides

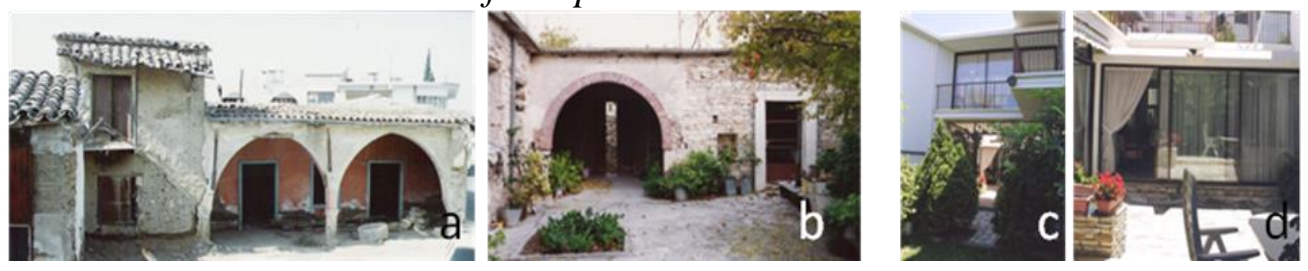

A close investigation of the bioclimatic features and sustainable development of vernacular architecture showed a very small fluctuation in the temperatures in the interior of traditional dwellings compared with the larger fluctuation of the external environment. It also underlined the microclimatic significance of the central yard keeping the temperature at a higher level during winter.

\section{Social Continuities and Discontinuities in Vernacular Architecture}

The existence of a social continuity in vernacular architecture is extremely important. Until recently a continuity in traditional living and building culture of architectural heritage has been observed. The architecture of traditional settlements has been a living and invaluable testimony to the historic memory of each place. Their essence depends not only on the fabric of the buildings, structures and spaces but on the ways they are used and appreciated, the 
traditions and intangible associations attached to them. Their social form and very often their close connection with agriculture and primary production are very important. The traditional knowledge of craftsmen is also part of the cultural heritage and can be considered as a cultural resource.

This continuity - obvious for many years - has changed recently. The relationship of people to the traditional environment that was noted during previous periods as a close relationship between people and the traditional environment - has been interrupted since the new lifestyle has created new requirements. Unfortunately in many cases there is a change in the society that uses these traditional settlements as a large number of residents leave behind their traditional settlements which are either left abandoned or are being reused by new owners.

A romantic nostalgia towards the past has replaced the traditional continuity between the past and the present. Radolf Starn (2002) stated "People with the feel of continuity and tradition do not need to preserve the past as such. This is a modern western preoccupation". The relationship between traditional settlements and contemporary society has constituted the subject of many discussions and debates. Some questions that have arisen are "What is the impact of living in traditional dwellings on human feelings?" "Are local architectural traditions in conflict with contemporary human behavior? (Denslagen 2009)" "How can traditional buildings affect contemporary society and people who inhabited these dwellings?"

Life in a traditional environment today as in the past generates beneficial effects on human emotions as it helps people come in contact with the environment and with more authentic ways of life and living, being closer to nature and meeting new experiences. In addition traditional shells, with the necessary adjustments can meet the needs of a contemporary way of living and thereby provide a healthier environment for people.

\section{Continuity and Discontinuity in the Conservation of Vernacular Architecture}

The beginning of the conservation is related to the contemporary way of keeping alive and genuine the relationship with the cultural works of the past after the industrial revolution and the development of historical consciousness which interrupted the traditional continuity of social, cultural and economic life.

The romantic nostalgia towards the past has led to the conservation and reuse of traditional buildings following a different approach compared with previous periods. Whereas in the past a tactic of segmented partial and ongoing maintenance with minor modifications in order to adapt a building to the needs of its successive owners was followed without interrupting its continuity and use, today this attitude has changed dramatically.

Most of the extensions, additions or conversions are implemented with some interruption to the continuity of the traditional structure. Financial grants 
for the traditional buildings require the preparation of plans, licensing operations and thus an integrated, complete and thorough maintenance often resulting in a complete transformation of a building which sometimes acquires a new appearance.

Traditional architecture is thus considered and maintained as something remote from the present, which is not being experienced in the same daily and practical way as in the past. Initially a sharp but conscious interruption of the course of life of traditional buildings takes place and then a comprehensive restoration and revitalization plan is implemented.

Kees van der Ploef, states that whereas the world has undergone huge changes over the past century all the restored facades look so bright and new that they give us the illusion that we are still living in the last centuries (Denslagen 2009). The historic and traditional buildings in these cases are not allowed of becoming genuinely old. At the first trace of dilapidation, they are rescued and are made as good as new. Patina that constitutes a very important part of the old buildings closely connected with their age value and authenticity is thus removed. According to Wim Deslagen (2009) "The image of the cities that has grown historically over the centuries cannot be put on ice during conservation". The beauty of an old city is the product of a long series of changes that occurred during the past and for the sake of this specific beauty this process should be allowed to continue. "Time never ceases to advance and there is no way of stopping it". Thus every generation has the right to express itself culturally with its own forms in architecture and planning.

The question remains then what conservationists should be aiming for? Should they nurture the illusion that time has stood still, or should they permit the city to evolve in relation to modern urban activities? The answer to this question lays somewhere in between the two above mentioned options. Modern contemporary urban development cannot be stopped, therefore permitting the evolution of the city with the erection of contemporary structures and additions that are in harmony with the existing historic buildings without imposing them. At the same time the existing fabric and the different historical layers of the city are to be respected with the preservation of the most significant and important buildings and neighborhoods.

The restoration and revival of traditional buildings requires an effort of setting up a philosophical discourse on the concept of "continuity" in the construction phases, so often hidden within the buildings studied. Should our most recent interventions come as a natural consequence of the past or as a rupture with the previous phases? Should the contemporary interventions in a historic environment follow the morphology of the existing structures?

\section{Architectural Morphological Continuity and Discontinuity in Design Intervention}

The architectural morphological continuity no more exists as one of the acceptable approaches to the intervention since the completion of the image of a historic urban tissue is now being carried out with a contemporary architectural and structural expression. At the same time according to the 
Washington Charter "a degree of artistic self-restraint is recommended in the erection of new structures and additions in a historic environment. When it is necessary to construct new buildings or adapt existing ones, the existing spatial layout should be respected especially in terms of scale and size" (Figure 4).

Figure 4. Conservation of a Traditional Settlement with the Addition of New Contemporary Structures
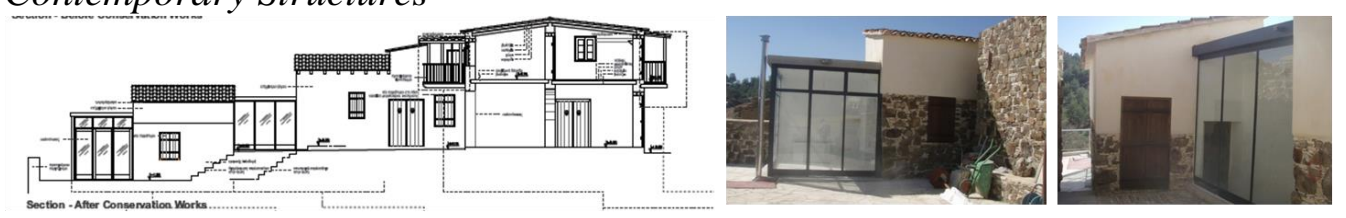

Giovannoni underlines the respect for the conditions of the setting of historic buildings, which should not be altered by inappropriate isolation or by the construction of new adjacent buildings incompatible in massing, color, or style. When filling empty gaps in a traditional urban area a continuity in the urban fabric that follows the detached system is achieved but at the same time a discontinuity in morphology is created as the completion is desired to be carried out with a contemporary architectural concept, so that the new will differ from the old with regard to the materiality and form, bearing the stamp of its time. Mario Botta also remarks: The old needs the new in order to be recognizable and the new needs the old in order to engage in a dialogue with it (Denslagen 2009).

Another issue related with the revival of historic and vernacular buildings of historic centers is connected with the reconstructions of buildings that have been completely destroyed. According to Wim Denslagen (2009) reconstructions of buildings (historic or traditional) that have been completely demolished, can restore one's ties with the past and evoke a feeling of continuity, as they have a useful function in restoring the identity of a city and history, a region or a country.

On the other hand, according to many international charters (Charter of Venice) "All reconstruction work should however be ruled out a priori". The value of a historical monument is connected with its material age, including the traces that time has left in its structure, none of which can be repeated or imitated. The creation of a timeless state is as undesirable as the reconstruction of the original appearance, because in both cases the progress of time is denied.

The demolition of a monument can even have some historical value. When a monument is deliberately destroyed, its reconstruction would mean a revision of history something that is morally unacceptable and a form of improper manipulation. An artwork can only be created once. A copy is a forgery of the authentic work by definition. Imitation cannot claim any respect, because it lacks the genuine atmosphere of its own age. When conserving the authentic fabric of vernacular and historical buildings with missing parts and especially those in a ruinous condition a main question arises related with the form of the intervention. How is the potential integrity of traditional buildings in a ruinous 
condition achieved? Is "architectural morphological continuity' allowed in this case?

Although in the previous decades that was the case, now this attitude has changed. The completion of the image of a building of the past today is not being carried out in a stylistic way. The distinction between the ruins and the new parts of the structures is very often a prerequisite, especially when dealing with important buildings. The potential unity that Brandi (1963) proclaims, expressed also by Philippot refers to the conservation of the continuity of lakounas - ie vacant areas of works of the past - using a new architectural style and materials. Giovannoni underlines that continuity does not mean denying change but, rather, managing and integrating it.

While all around the world there are numerous examples of restoring the integrity and continuity of ruin monuments with the use of contemporary materials in Cyprus very often a more conservative approach towards the maintenance of ruins is observed (Figure 5). Ruins are conserved in their existing condition if there is not enough evidence about their original form or a completion of parts of the monuments, using the same materials, is being carried out sometimes with a distinctive indication of a boundary line between the authentic material and the new elements added. During such projects some questions arise regarding the new final form of ruins due to the partial reconstruction of the materiality of the structures. In many cases especially during the conservation of simple traditional houses the completion is achieved without any distinction between the old and the new avoiding any interruption of the authentic character of their historic area but leading to a confusion between the old and new (Figure 5).

\section{Continuity and Discontinuity in Materiality during Conservation}

The materiality and the fabric of traditional buildings constitute important elements during conservation. The relation of the materiality with the authenticity of a monument is underlined by the Venice Charter referring mainly to Western civilizations. Today vernacular buildings are usually conserved using traditional materials and techniques similar to the original ones, following the principles of the ICOMOS Charter on Built Vernacular Heritage (1999) and thus underlining the importance of the continuity of traditional building systems and craft skills. Reversibility and re-treatability also help towards the preservation of the integrity of the original text and the possibilities for alternative interpretations in the future (Matero 2007). In the case of ephemeral building materials (that can be observed sometimes in the western civilization but mainly in non-European cultures) the repeated replacement of the dilapidated parts is inevitable, leading to a different concept regarding authenticity (Nara declaration). 
Figure 5. Different Strategies for Completing the Form of Traditional Dwellings a: with the Use of New Materials and Style, b,c: without any Distinction between the Old and New
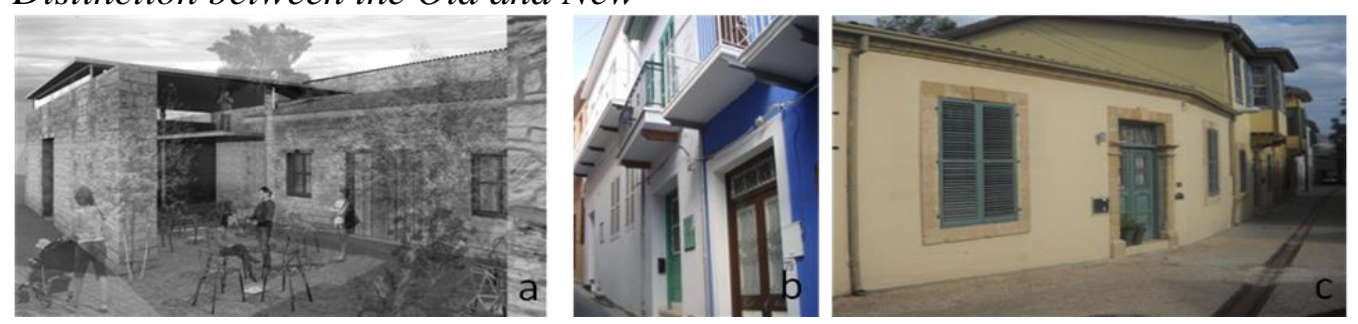

\section{Social Continuity and Discontinuity during Conservation}

Very often when conserving a traditional dwelling there is an apparent need for changing its use. When traditional buildings and complexes are being reused by the same residences for the same function a kind of continuity is being ensured. Social changes and economic factors and more specifically the new requirements that traditional buildings are invited to meet interrupt their life and continuous use. Characteristic examples of rehabilitation schemes are the traditional villages and urban centers of the island, where extensive plans for the regeneration and revitalization of old neighborhoods are being carried out (Chrysaliniotissa - Nicosia, etc.). In Limassol, an organized redevelopment of existing historic and vernacular buildings for university uses has been recently carried out for the integration of the Technical Cyprus University in the historical center of the city. The reuse of these buildings led to social and architectural changes and to various effects to the rest of the city's building stock - with the conversion of other traditional buildings to student homes, entertainment and recreation centers. Thus the change of use of a group of buildings leads to a chain of social and structural changes in the town centers, ensuring the continuity of life but causing at the same time an interruption to the social continuity. This functional change if not handled properly can lead to the abandonment of the old occupants of the town with negative effects.

\section{Conclusions}

The Declaration of Amsterdam underlines the necessity of continuity of existing social and physical realities in urban and rural communities. According to the Icomos Charter of Vernacular Architecture where there is no break in the continuous utilization of vernacular forms, a code of ethics within the community can serve as a tool of intervention.

Economic crisis reinforces the necessity of reusing existing structures, instead of building new ones. Territory, contemplative and productive landscapes of traditional settlements constitute an essential framework of the traditional culture of different peoples and cultures, their materials and technologies, their typologies and expressions, their identity and the anthropological traces of the communities placing man and his actions at the center of every relative research. 
Vernacular architecture is a living organism that grows over time and it cannot be put on ice during conservation. Despite its continuities, it has been changed and transformed according to the social and economic conditions of each era and it has been adapted to the different conditions of each period of culture. Consequently both the continuities and the discontinuities mentioned above are essential parts of its life and progress through time.

\section{References}

Brandi, C.1963. Teoria del Restauro, Rome: Edizioni di storia e Latteratura.

Denslagen, W. 2009. Romantic Modernism. Nostalgia in the World of Consevation, Amstardam. Amstardam University Press.

Matero, F.G. 2007. 'Loss, Compensation and Authenticity: The contribution of Cesare Brandi to Architectural Conservation in America', Future Anterior 4 (1), 45-55.

Michael, A. and Philokyprou, M. 2013. "The Contribution of the Courtyard to the Environmental Perception of Residential Architecture in Cyprus", Proceedings of 4th International Conference Renewable Energy Sources \& Energy Efficiency, New Challenges, Nicosia, Cyprus, June 6-7, 2013, 166-178.

Paul Oliver. 2005. Encyclopedia of Vernacular Architecture of the World, Cambridge University Press.

Philokyprou, M. 2009. "Architecture of Pano and Kato Pyrgos Tyllirias" Proceedings of the conference, Tylliria. Memories, History and Archaeology, Kato Pyrgos, Cyprus, 4-5 May 2009, 441-470 (in Greek).

Philokyprou, M. 2011. "The Initial Appearance of Ashlar Stone in Cyprus. Issues of Provenance and Use", Mediterranean Archaeology and Archaeometry, International Scientific Journal, Vol. 2011, No.2, 37-53.

Starn Radolf 2002. Authenticity and Historic Preservation towards an authentic history, History of Human Sciences 15 (1):1-16. 